Anna Wawrzeńczyk ${ }^{1}$, Marzena Anaszewicz ${ }^{1}$, Wioletta Banaś ${ }^{1}$, Marta Spychalska-Zwolińska ${ }^{1}$, Ewa Socha², Kinga Lis², Magdalena Żbikowska-Gotz², Zbigniew Bartuzi², Jacek Budzyński ${ }^{1}$

${ }^{1}$ Department of Vascular and Internal Diseases, Faculty of Health Sciences, Ludwik Rydygier Collegium Medicum in Bydgoszcz, Nicolaus Copernicus University in Toruń, Poland

2Department of Allergology, Clinical Immunology and Internal Diseases, Faculty of Medicine, Ludwik Rydygier Collegium Medicum in Bydgoszcz, Nicolaus Copernicus University in Toruń, Poland

\title{
Relationship of serum leptin with parameters of nutritional status and body composition among patients with stable course of cardiovascular disorders
}

\section{Corresponding author:}

Jacek Budzyński, Department of Vascular and Internal Diseases, Faculty of Health Sciences, Ludwik Rydygier Collegium Medicum in Bydgoszcz, Nicolaus Copernicus University in Toruń, Poland, email: budz@cps.pl
Medical Research Journal 2018; Volume 3, Number 2, 89-97 10.5603/MRJ.2018.0015 Copyright (c) 2018 Via Medica ISSN 2451-2591

\begin{abstract}
Background: Blood leptin concentration is related to fat mass, adipose cell and leptin receptor function, and comorbidities. The aim of this study is to determine the relationships between blood leptin concentration and nutritional status assessment among inpatients with stable cardiovascular disorders.

Materials and Methods: Blood leptin concentration and nutritional risk and status assessments using clinical, anthropometric and biochemical parameters, as well bioelectrical impedance (BIA), were determined in 160 consecutive inpatients with mild exacerbation of cardiovascular diseases cardiovascular disorders undergoing non-urgent hospitalization.

Results: Patients with lower values of Minimal Nutritional Assessment score had lower blood leptin concentration and lower value of leptin to CRP ratio. Compared to patients with leptin concentration in the upper quartiles, individuals in the lowest quartile had a lower BMI and fat mass, thinner skinfolds, greater skeletal muscle mass and handgrip strength. In comparison with the values for leptin-to-CRP ratio, albumin, albumin-to-CRP ratio and lymphocyte count, leptin explained a greater part of the variance in the majority of parameters of nutritional status and body composition. Contrasting associations of leptin with ideal (negative) and current (positive) body mass were found.

Conclusions: Leptin was associated with parameters of nutritional status assessments more strongly than other biochemical parameters usually used. However, the use of leptin as a biomarker of nutritional status should be approached carefully and needs further evaluation, especially in the context of its strong association with both current and ideal body mass, the importance of receptors' resistance to leptin, and leptin's negative relationships with muscle mass and strength.

Key words: leptin; nutritional status assessment; nutritional risk; cardiovascular disorders
\end{abstract}

Med Res J 2018; 3 (2): 89-97

\section{Introduction}

Body composition is an important prognostic biomarker for inpatients [1]. It concerns patients' nutritional status, metabolic rate and cardio-metabolic risk. We now have a number of indices of nutritional risk and status assessment [2-3], the majority of which concern patients' malnutrition. However, obesity is also recognized as an important contributor to many metabolic dis- orders, including diabetes mellitus, hypertension, and dyslipidemia [4-6]. Obesity is also linked with the risk of functional impairment, cardiovascular event, in-hospital death, perioperative complications and prolongation of in-hospital stay [7-9]. The essence of obesity is excessive adipose tissue accumulation. However, adipose tissue not only plays a role in energy storage, but is also the source of the majority of substances, called adipocytokines, which regulate many of the process- 
es in both the endocrine and paracrine pathways [5]. One such substance is leptin. Leptin takes part in the long-term regulation of energy intake, and decreases appetite level in relation to energy storage (it is known as the satiety hormone) through the central inhibition of the secretion of orexigenic substances. Moreover, leptin induces activation of peripheral sympathetic nerve activity, leading to increased energy expenditure; it restores and regulates hypothalamic neuroendocrine axes, including the thyroid, gonadal, adrenocorticotropic hormone (ACTH)-cortisol and growth hormone axes [6, 10]; plays a role in muscle-bone crosstalk [11], the central regulation of physical activity [12], age-related fat accumulation in muscles [13], and neurocognitive processes, emotions, and memory [6]; affects some of the pathophysiological processes in the cardiovascular system, such as the promotion of left ventricular hypertrophy, vascular remodeling, hypertrophy, angiogenesis, and the proliferation of neointimal and vascular smooth muscle cells; takes part in atherosclerosis processes [5, 7]; and is recognized as a mediator inducing the survival, proliferation, invasion, migration, angiogenesis and anti-apoptosis of cancer cells, especially in patients with so-called obesity-related neoplasms (e.g. prostate, colorectal, and breast) [14]. The pathophysiological importance of leptin in the course of the aforementioned disorders is related not only to the level of adipose tissue accumulation, but also to dysfunction of adipocytes, which is becoming increasingly understood, especially in patients with obesity and/or metabolic syndrome [15].

As leptin is secreted by adipose tissue, it would seem to be a potential biomarker of patients' nutritional status, especially at the level of energy storage. However, the clinical importance of leptin does not appear to have been fully identified. The aim of this study is to determine the relationships between blood leptin concentration and several nutritional risk and status assessment scores among inpatients admitted due to cardiovascular disorders.

\section{Material and Methods}

\section{Patients}

The participants were 160 patients who required scheduled hospitalization in an internal medicine ward due to mild exacerbation of cardiovascular diseases (persistent atrial fibrillation, life-limiting intermittent claudication, stable angina pectoris, and hypertension). The exclusion criteria were: history or clinical signs of inflammatory processes or neoplasm; significant decrease in body weight during the three months prior to the current hospitalization (i.e. quotient of [100\% $\times$ (usual weight — actual weight) / usual body weight] being greater than 5\%); history of disorders affecting food intake or absorption; disturbance in nutritional status as a cause of hospitalization; and lack of informed consent for participation in the study.

During the first day of hospitalization, a medical history was obtained from each of the inpatients enrolled to the study and a physical examination performed, including assessment of anthropometric parameters of nutritional status. The inclusion and exclusion criteria were checked on the basis of these data. One year after the hospitalization during which the leptin blood concentration was determined, a follow-up call was made to all the patients or their family members, who were asked questions concerning survival, reason for admission if hospitalized, and current functional status.

\section{Biochemical determinations}

The day after admission, blood samples were taken from the patients' ulnar vein between 7 am and 8 am while they were in a fasting state. The following biochemical determinations were performed in the hospital's diagnostic laboratory using standard methods: blood morphology, low-density lipoprotein (LDL) cholesterol, triglycerides, glucose, albumin, C-reactive protein (CRP), absolute lymphocyte count, and thyrotropin-stimulating hormone (TSH). Laboratory determinations were performed in the hospital's diagnostic laboratory using standard methods.

The blood samples for leptin determination were centrifuged at $4{ }^{\circ} \mathrm{C}$ and $3600 \mathrm{rev} / \mathrm{min}$. The serum obtained was stored at $-80^{\circ} \mathrm{C}$ until determination. Leptin determination was performed using an ELISA kit by ALPCO (cat. no 11-LEPHU-E01) in accordance with the manufacturer's instructions.

\section{Scores of nutritional risk}

The following nutritional risk assessment surveys were performed: Nutritional Risk Screening-2002 (NRS2002) [2], Mini Nutritional Assessment (MNA) [16], and Geriatric Nutritional Risk Index (GNRI) [17, 18].

\section{Parameters of nutritional status assessment}

A nutritional status assessment was performed for all the study participants. The following parameters were measured: height $(\mathrm{cm})$, body weight $(\mathrm{kg})$, waist circumference (WC, cm), hip circumference ( $\mathrm{HC}, \mathrm{cm})$, mid-arm circumference (MAC, cm), mid-calf circumference (MCC, $\mathrm{cm}$ ), triceps skinfold thickness (TSF, mm), biceps skinfold thickness (BSF, mm), subscapular skinfold thickness (SST, mm), abdominal (suprailiac) skinfold thickness (AST, mm), knee height (cm), as well as the handgrip strength of the predominant and non-predominant hands. All circumferences were measured using tape, 
skinfolds using a Harpender MG-4800 skinfold clockwork caliper (produced by BATY, UK), and handgrip strength using an electronic dynamometer (manufactured by Kern, Germany). Body composition was determined using bioelectrical impedance analysis (BIA) and a TANITA BC 420 MA device (TANITA Corporation, Tokyo, Japan). The following parameters were analyzed: fat mass (FM; \% and $\mathrm{kg}$ ), visceral fat level (ranged 1-59, level $>26$ shows on abdominal fat distribution), fat-free mass (FFM, kg), predicted muscle mass (PMM, kg), skeletal muscle mass (\%), bone mass (BM, kg), total body water (TBW, \%, kg), body mass index $\left(\mathrm{BMI}, \mathrm{kg} / \mathrm{m}^{2}\right)$, basal metabolic rate (BMR, kcal), and metabolic age (MA, years).

The following secondary parameters were calculated based on the above-mentioned indices [2-3]:

- an "ideal weight" was calculated according to the Lorentz formula: for female patients, ideal weight $=$ [height $(\mathrm{cm})-100]-\{$ [height (cm) - 150]/2\}; and for male patients, ideal weight $=$ [height $(\mathrm{cm})-100]-\{$ height $(\mathrm{cm})$ - 150]/4\} [18];

- absolute (actual [current] — ideal body weight) and proportional $(100 \% \times$ [actual — ideal body weight] / actual body mass) differences between actual and ideal body weight (excess of body mass);

- the quotient of actual (current) to ideal body mass $\times 100 \%$;

- GNRI according to the following formula [18]: GNRI $=1.519 \times$ blood albumin concentration $+41.7 \times$ actual body mass (current weight) /ideal body mass [18-19];

- mid-arm muscle circumference (MMC) according to the following formula: MMC $=$ MAC $-\varpi \times$ TSF (in this study, a value of 3.14 was substituted for $\varpi$ );

- arm muscle area (AMA) according to the following formula: $A M A=\left\{[M A C-(0.314 \times T S F)]^{2} /(4 \varpi)\right.$;

- arm fat area (AFA) according to the following formula: $\mathrm{AFA}=\left(\mathrm{MAC}^{2} / 4 \varpi\right)-\left[(\mathrm{MAC}-(0.314 \times \mathrm{TSF})]^{2} /(4 \varpi) ;\right.$

- brachial adipo-muscular ratio (BAMR) according to the following formula: BAMR = AFA / AMA;

- blood-leptin-to-CRP ratio;

- blood-albumin-to-CRP ratio;

- blood albumin in one of the following ranges: < 2.5 g/l; 2.5-3.0 g/l; 3.0-3.5 g/l; $\geq 3.5 \mathrm{~g} / \mathrm{l}$;

- blood lymphocyte count in the following ranges: < $800 \mathrm{G} / \mathrm{l} ; 800-1200 \mathrm{G} / \mathrm{l} ; 1200$ $1500 \mathrm{G} / \mathrm{l} ;$ > $1500 \mathrm{G} / \mathrm{l}$;

- the difference between actual (metric) and metabolic age determined using BIA.

\section{Bioethics}

The investigation was conducted in compliance with the Declaration of Helsinki for medical research, after receiving permission from local Bioethical Committee
No. 389/2015. Each patient gave written consent to participating in the study.

\section{Statistics}

Statistical analysis was conducted using licensed versions of statistical software STATISTICA (a data analysis software system), StatSoft, Inc. (2015), version 12. The normal distribution of the study variables was checked using the Shapiro-Wilk test. The results were mainly presented as the mean \pm standard deviation, or $\mathrm{n}, \%$. The statistical significance of differences between groups was verified using the Student's t-test, U Man Whitney-test and $\mathrm{Chi}^{2}$ test. Pearson's linear correlations were determined. Stepwise backward multiple regression (using the General Regression Models module) was applied to check the relationships between the values of the blood leptin concentration and the demographic data, and parameters of nutritional status. Subjects' age, gender, history of atrial fibrillation, diabetes mellitus, and chronic heart failure, as well as such parameters of nutritional status, as: MNA total score, actual and ideal body mass, percentage of fat mass, skeletal muscle mass, visceral fat level were selected as the independent variables. The statistical significance level was set at a $p$-value $<0.05$.

\section{Results}

Patients with MNA score in the lowest quartile (Q1; MNA score $\leq 23$ ) had significantly lower blood leptin concentration than subjects in the second (Q2; < 23MNA score $\leq 25)$ MNA quartile (Q1 vs. Q2: $34.64 \pm 33.94$ vs. $51.62 \pm 37.82 \mathrm{pg} / \mathrm{ml}$; $p=0.042)$. Moreover, compared to subjects with MNA score between 17 and $23(n=51)$, patients with MNA score greater or equal to 24 ( $n=105$ ) had significantly greater ratio of blood leptin and CRP concentrations (24.94 \pm 26.63 vs. $14.04 \pm 13.70 \mathrm{pg} / \mathrm{ml} ; \mathrm{p}=0.009)$. Similarly, subjects with MNA score in Q1 had significantly lower value of blood leptin to CRP ratio than subjects with MNA score in Q3 and Q4.

On the other hand, compared to the other quartiles, patients with a blood leptin concentration in the lowest quartile had significantly lower actual body mass and BMI (Tab. 1), and thinner tricuspid, scapular and abdominal skinfolds, and lower MAC and BAMR (data not presented). In relation to the third and fourth quartiles individuals from the lowest quartile of blood leptin concentration had significantly greater ideal body mass calculated in accordance with the Lorentz formula, and greater handgrip strength in the predominant hand. Compared to the other blood leptin quartiles, patients in the lowest quartile for blood leptin concentration also 


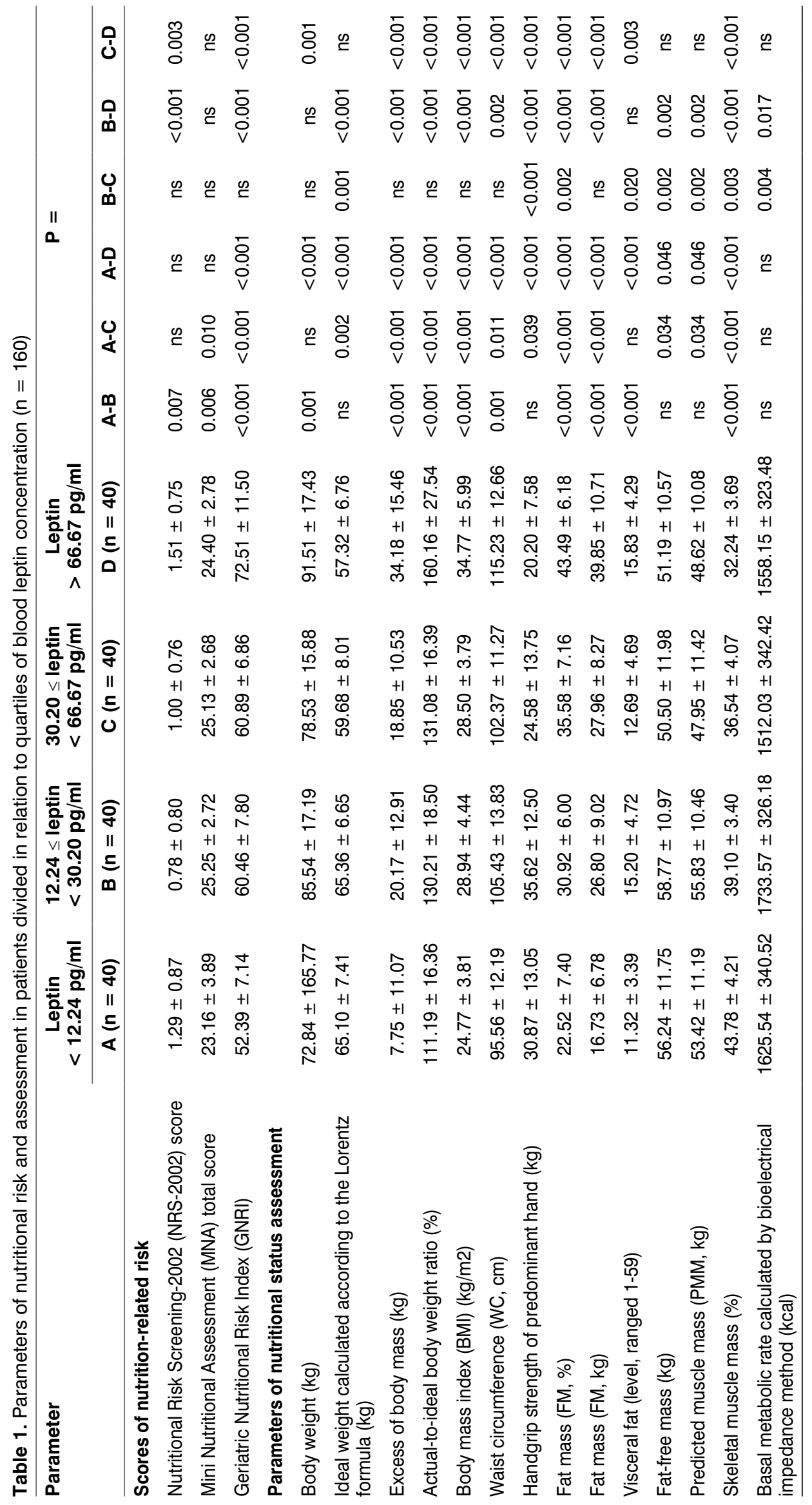


had a lower excess body mass, lower fat mass and visceral fat level. Whereas, predicted muscle mass and skeletal muscle mass were greater in subjects in the lowest blood leptin concentration quartile compared to the uppermost quartile. Basal metabolic rate was the highest in the second quartile of leptin blood concentration. However, patients with a blood leptin concentration in the uppermost quartile compared to individuals with blood leptin concentration from the lower quartiles were significantly older and were less likely to be male (Tab. 2). Patients with blood leptin concentration in the lowest quartile had also a lower prevalence of diabetes mellitus, cardiac heart failure, chronic kidney disease, and atrial fibrillation than individuals with blood leptin concentration in uppermost quartile (Tab.2).

We next calculated the linear correlations between blood concentrations of leptin, albumin, ratios of leptin-to-CRP and blood albumin-to-CRP, and blood lymphocyte count with the values of the scores of nutrition-related risk and anthropometric parameters analyzed for nutritional status assessment (Tab. 3). In comparison with the values of the leptin-to-CRP ratio, blood albumin concentration and blood lymphocyte count, the blood leptin concentration correlated significantly with a greater number of the analyzed parameters of nutritional status assessment. Moreover, blood leptin concentration explained the greater part of the variance in the majority of the parameters of nutritional status, especially when they concerned fat mass, determined in anthropometric measurements (e.g. skinfolds), or using BIA. On the other hand, the blood leptin concentration had no statistically and clinically significant relationships with nutritional risk indices, such as the NRS-2002, and MNA.

Taking into account the role of leptin in obesity pathogenesis (as the satiety hormone and an inductor of energy expenditure), we also analyzed the relationships between blood leptin concentration and ideal and actual body weight, basal metabolic rate (BMR) and metabolic age (Tab. 3). We found that blood leptin concentration was positively correlated with actual body weight (Fig.1) and fat mass, but negatively with ideal body mass (Tab. 3, Fig. 2). Moreover, blood leptin concentration was also strongly related to metabolic age but not to BMR. However, after adjustment in stepwise backward multiple regression multiple regression method only CHF, actual and ideal body mass, and visceral fat level remained significant determinant of blood leptin concentration (Tab. 4)

Neither the median value nor any of the quartile values of blood leptin concentration were statistically significantly associated with risk of all-cause mortality (nine patients died during the one-year follow-up, $p=0.429$ and $p=0.337$, respectively) and readmission (during the one-year follow-up, 29 patients

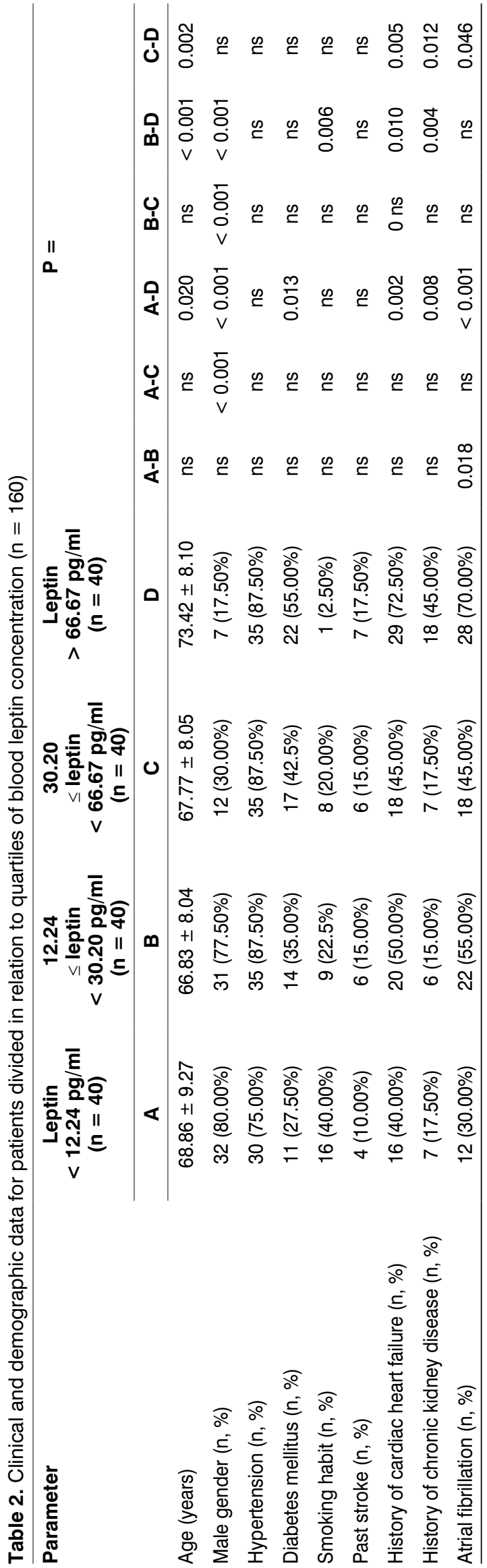




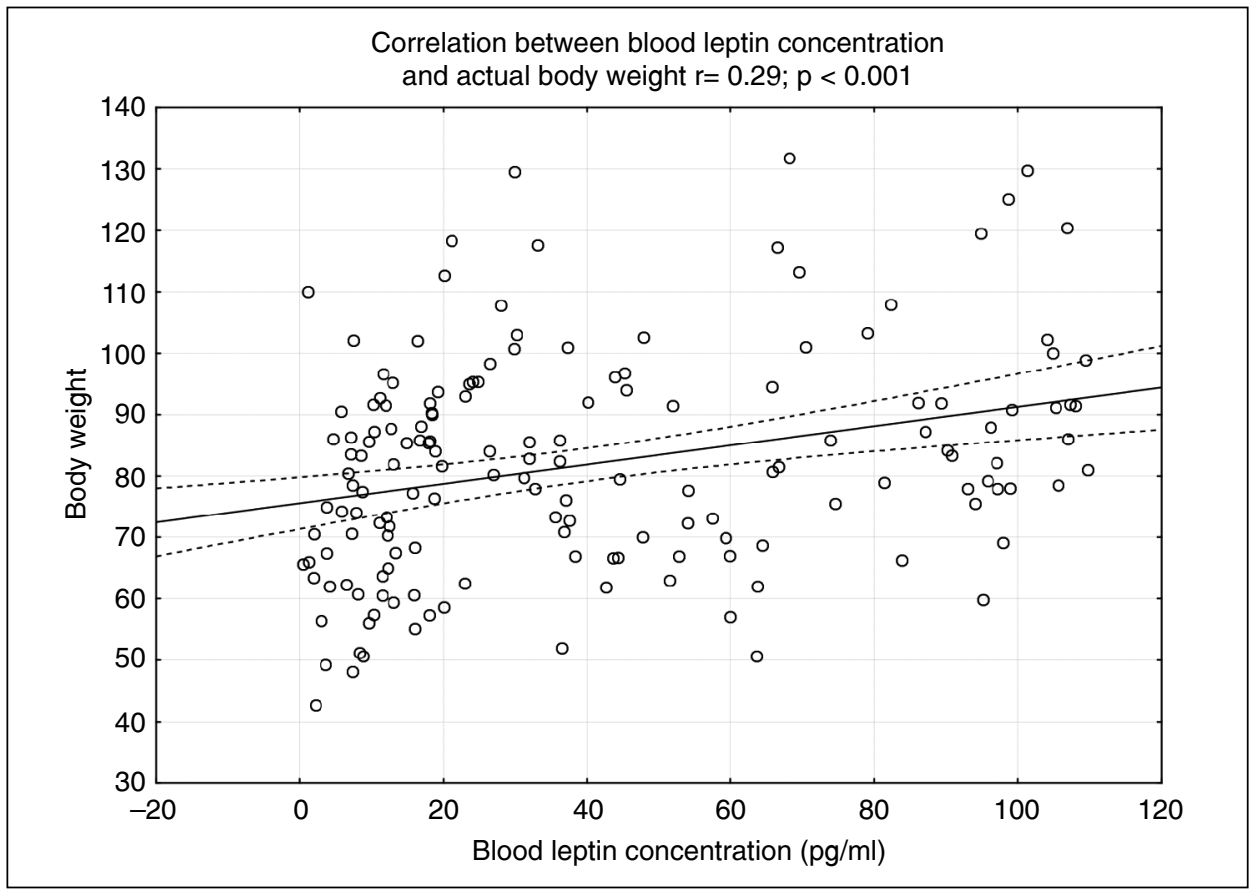

Figure 1. Correlation between blood leptin concentration and actual body mass

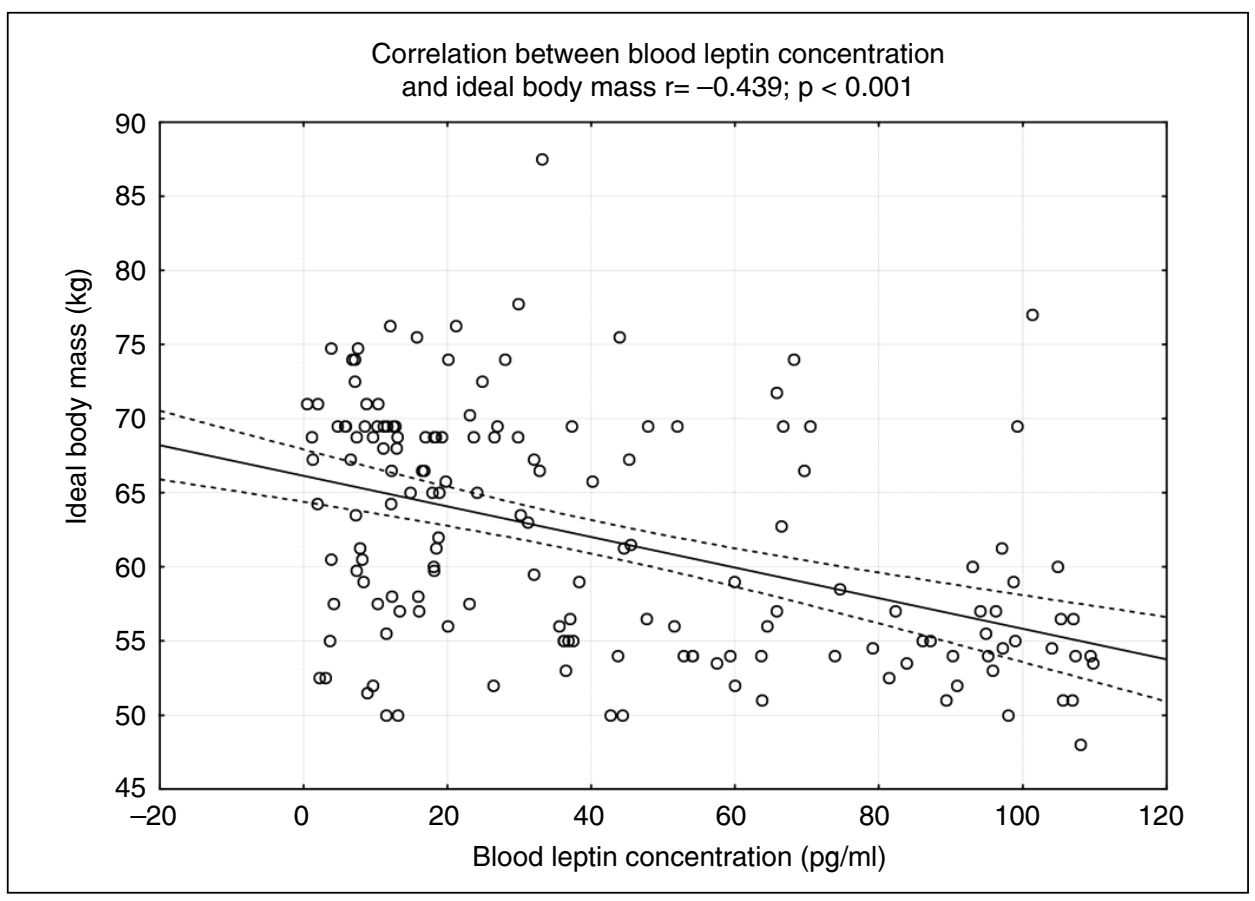

Figure 2. Correlation between blood leptin concentration and ideal body mass

were readmitted due to any cause; $p=0.344$ and $p=0.344$, respectively) subsequent to the oneyear follow-up phone call (data not presented in detail).

\section{Discussion}

In this study, performed among inpatients without significant weight loss during the three months prior to 
Table 3. Leptin blood concentration correlation with nutritional risk and nutritional assessment parameters $(n=160)$

\begin{tabular}{|c|c|c|c|c|c|}
\hline Parameter & $\begin{array}{l}\text { Blood leptin } \\
\text { concentration }\end{array}$ & $\begin{array}{l}\text { Leptin-to-CRP } \\
\text { ratio }\end{array}$ & $\begin{array}{l}\text { Blood albumin } \\
\text { concentration }\end{array}$ & $\begin{array}{l}\text { Albumin-to- } \\
\text { CRP ratio }\end{array}$ & $\begin{array}{c}\text { Blood } \\
\text { lymphocyte } \\
\text { count }\end{array}$ \\
\hline $\begin{array}{l}\text { Nutritional Risk Screening-2002 } \\
\text { (NRS-2002) score }\end{array}$ & ns & ns & $\begin{array}{l}R=-0.25 \\
p=0.001\end{array}$ & $\begin{array}{l}R=-0.29 \\
p<0.001\end{array}$ & ns \\
\hline $\begin{array}{l}\text { Mini Nutritional Assessment (MNA) } \\
\text { score }\end{array}$ & ns & $\begin{array}{l}R=0.24 \\
p=0.003\end{array}$ & $\begin{array}{l}R=0.35 \\
p<0.001\end{array}$ & $\begin{array}{l}R=0.20 \\
p=0.01\end{array}$ & ns \\
\hline $\begin{array}{l}\text { Geriatric Nutritional Risk Index } \\
\text { (GNRI) }\end{array}$ & $\begin{array}{l}R=0.64 \\
p<0.001\end{array}$ & $\begin{array}{l}R=0.18 \\
p=0.03\end{array}$ & ns & $\begin{array}{l}R=-0.21 \\
p=0.01\end{array}$ & $\begin{array}{l}R=0.24 \\
p=0.003\end{array}$ \\
\hline Age (years) & $\begin{array}{l}R=0.24 \\
p=0.002\end{array}$ & ns & ns & $\begin{array}{l}R=-0.18 \\
p=0.026\end{array}$ & ns \\
\hline Male gender & $\begin{array}{l}R=-0.53 \\
p<0.001\end{array}$ & $\begin{array}{l}R=-0.27 \\
p<0.001\end{array}$ & ns & ns & ns \\
\hline Actual body weight (kg) & $\begin{array}{l}R=0.30 \\
p<0.001\end{array}$ & ns & ns & $\begin{array}{l}R=-0.16 \\
p=0.048\end{array}$ & $\begin{array}{l}R=0.19 \\
p=0.02\end{array}$ \\
\hline $\begin{array}{l}\text { Ideal body mass (Lorentz formula, } \\
\mathrm{kg} \text { ) }\end{array}$ & $\begin{array}{l}R=-0.44 \\
p<0.001\end{array}$ & $\begin{array}{l}R=-0.22 \\
p=0.006\end{array}$ & ns & ns & ns \\
\hline Actual-to-ideal body mass ratio (\%) & $\begin{array}{l}R=0.64 \\
p<0.001\end{array}$ & $\begin{array}{l}R=0.16 \\
p=0.046\end{array}$ & ns & $\begin{array}{l}R=-0.23 \\
p=0.003\end{array}$ & $\begin{array}{l}R=0.24 \\
p=0.002\end{array}$ \\
\hline Body mass index (BMI) (kg/m2) & $\begin{array}{l}R=0.60 \\
p<0.001\end{array}$ & ns & ns & $\begin{array}{l}R=-0.22 \\
p=0.005\end{array}$ & $\begin{array}{l}R=0.21 \\
p=0.008\end{array}$ \\
\hline Waist circumference (WC, cm) & $\begin{array}{l}R=0.44 \\
p<0.001\end{array}$ & ns & ns & $\begin{array}{l}R=-0.22 \\
p=0.005\end{array}$ & ns \\
\hline $\begin{array}{l}\text { Handgrip strength of predominant } \\
\text { hand }(\mathrm{kg})\end{array}$ & $\begin{array}{l}R=-0.41 \\
p<0.001\end{array}$ & ns & $\begin{array}{l}R=0.17 \\
p=0.03\end{array}$ & $\begin{array}{l}R=0.17 \\
p=0.04\end{array}$ & ns \\
\hline Fat mass determined by BIA (FM, \%) & $\begin{array}{l}R=0.74 \\
p<0.001\end{array}$ & $\begin{array}{l}R=0.35 \\
p<0.001\end{array}$ & ns & ns & ns \\
\hline Fat-free mass (FFM, kg) & $\begin{array}{l}R=-0.23 \\
p=0.003\end{array}$ & $\begin{array}{l}R=-0.22 \\
p=0.005\end{array}$ & ns & ns & ns \\
\hline Predicted muscle mass (PMM, kg) & $\begin{array}{l}R=-0.24 \\
p=0.003\end{array}$ & $\begin{array}{l}R=-0.22 \\
p=0.006\end{array}$ & ns & ns & ns \\
\hline $\begin{array}{l}\text { Percentage of skeletal muscle mass } \\
\text { (\%) }\end{array}$ & $\begin{array}{l}R=-0.73 \\
p<0.001\end{array}$ & $\begin{array}{l}R=-0.35 \\
p<0.001\end{array}$ & ns & ns & ns \\
\hline $\begin{array}{l}\text { Level of visceral adipose tissue } \\
\text { (score) }\end{array}$ & $\begin{array}{l}R=0.25 \\
p=0.001\end{array}$ & ns & ns & ns & ns \\
\hline Basal metabolic rate (by BIA, kcal) & ns & $\begin{array}{l}R=-0.17 \\
p=0.028\end{array}$ & ns & ns & ns \\
\hline Metabolic age (MA, years) & $\begin{array}{l}R=0.59 \\
p<0.001\end{array}$ & $\begin{array}{l}R=0.22 \\
p=0.005\end{array}$ & ns & $\begin{array}{l}R=-0.22 \\
p=0.005\end{array}$ & $\begin{array}{l}R=0.15 \\
p=0.057\end{array}$ \\
\hline $\begin{array}{l}\text { Difference between metric and } \\
\text { metabolic age (years) }\end{array}$ & $\begin{array}{l}R=0.42 \\
p<0.001\end{array}$ & $\begin{array}{l}R=0.19 \\
p=0.02\end{array}$ & ns & ns & $\begin{array}{l}R=0.12 \\
p=0.014\end{array}$ \\
\hline
\end{tabular}

Abbreviations: data are presented as $\mathrm{R}$ and $\mathrm{p} ; \mathrm{BIA}=$ bioelectrical impedance analysis; CRP = C-reactive protein; ns- non-significant statistically

non-urgent admission to hospital due to cardiovascular disorders, we confirmed data from the literature [4-6, $15,19]$ that an increase in blood leptin concentration is positively associated with higher age and female gender and the prevalence of metabolic disorders and cardiovascular disorders, such as diabetes mellitus, chronic heart failure and atrial fibrillation (Tab. 2). Blood leptin concentration was also statistically significantly associated with the majority of the parameters of nutritional status assessments; however, its relation to scores of nutrition-related risk, such as NRS2002, MNA, and GNRI, had no clinical importance (Tab. 1, Tab. 3). A number of statistically significant correlations between blood leptin concentration and the parameters mentioned were found (Tab. 3); however, in multifactorial analysis only current and ideal body mass, visceral fat level and percentage of fat mass remained significant (Tab. 4). The values of the majority of the determination coefficients $\left(R^{2}\right)$ of these correlations were greater for leptin than for classic biochemical parameters of 
Table 4. Stepwise backward multiple regression analysis for respective parameters determining blood leptin concentration; $R^{2}=0.81$; adjusted $R^{2}=0.65 ; F=59.45 ; p<0.01$

\begin{tabular}{lcccc}
\hline Independent variable & $\beta$ & $\begin{array}{l}\text { Standard } \\
\text { error for }\end{array}$ & $\mathbf{t}$ & $\mathbf{p}$ \\
\hline Constant & & & 1.11 & 0.27 \\
CHF & 0.21 & 0.05 & 4.33 & $<0.001$ \\
Visceral fat level & -0.17 & 0.08 & -2.08 & 0.04 \\
Body weight (kg) & 0.34 & 0.09 & 3.70 & $<0.001$ \\
Ideal body mass (kg) & -0.33 & 0.08 & -3.94 & $<0.001$ \\
Fat mass (\%) & 0.55 & 0.08 & 6.84 & $<0.001$ \\
\hline
\end{tabular}

nutritional status assessment, such as blood albumin concentration, albumin-to-CRP ratio and blood lymphocyte count (Tab. 3). Our observations also corroborate outcomes reported by other authors [4-6, 15, 19]. It is known that leptin is a hormone produced in adipose tissue and, therefore, correlations between blood leptin concentrations and biomarkers of fat mass (BMI, waist circumference, BIA, and skinfold thickness) are to be expected. However, lack of association between leptin and WHR may be surprising (Tab. 1, Tab. 3).

In the authors' opinion, the most interesting observations obtained in this study were the negative correlation of blood leptin concentration and ideal body mass (Fig. 2) and the positive correlation with actual body mass (Fig. 1), excess body weight and the values of a lot of the indices of adipose tissue accumulation investigated (Tab. 3, Tab. 4). Moreover, patients from first and second quartiles of blood leptin concentration had significantly higher ideal body mass and lower excess of body mass than their counterparts with blood leptin concentration in the third and fourth quartiles (Tab. 1). We suggest that the only explanation of such opposing relationships between ideal and current body weight is a maximal level of sensitivity to leptin, determined individually (genetically and environmentally) and related to ideal body mass. In this context, negative associations between blood leptin concentration and excess current body mass (Tab. 1, Tab. 3, Tab. 4) correspond to leptin resistance described in patients with obesity $[6,10,20]$. To the best of our knowledge, this is the first such observation showing different relationships of blood leptin concentration to actual and ideal body mass. This may be of importance in explaining the not fully understood pathogenesis of overweight and obesity, especially as leptin is considered a potential tool for obesity therapy [6]. On the other hand, such therapy seems to have the potential to be effective in only a small number of patients with obesity and hypoleptinemia.

What may be surprising are the negative correlations between blood leptin concentration and indices of muscle mass and muscle strength (Tab. 3). However, these observations corroborate a study by Gubelmann et al. [21], who found negative correlations between log-transformed leptin and grip strength in a population-based sample in Lausanne. Bucci et al. [22] also suggested the contribution of age-related increases in fat mass and blood leptin concentration to age-associated physical inactivity, sarcopenia and loss of strength. In an investigation by Karvonen-Gutierrez et al. [8], higher baseline leptin concentrations predicted poorer mobility-based functioning, which is generally related to muscle mass. However, Rachakonda et al. [23] found a lower log-transformed leptin level in malnourished inpatients with end-stage liver cirrhosis. In this work, malnutrition was diagnosed, i.a. on the basis of a mid-arm circumference of less than $23 \mathrm{~cm}$, indicating sarcopenia. These results may have some impact on knowledge concerning muscle adipose tissue crosstalk [11], sarcopenic obesity $[13,24]$ and its organic complications, especially concerning liver steatosis [25], patients' functional status $[1,8]$, and obesity-related all-cause mortality $[4,26]$.

Although we found a number of statistically significant relationships between blood leptin concentration and parameters of nutritional status assessment (Tab. 2, Tab. 3, Fig. 1, Fig. 2), our observations should be interpreted with caution due to some limitations. Firstly, our study population was relatively small. Secondly, our study population did not consist of healthy people, but patients with stable cardiovascular disorders that only required scheduled hospitalization. Therefore, our results cannot be extrapolated to healthy individuals. Thirdly, patients' physical activity was not taken into account. However, work by Guerra et al. [27] shows an increase in blood leptin concentration after one week of bed rest. Exercise habits also had an effect on muscle mass and handgrip strength, and leptin seems to take part in the central regulation of physical activity in a dopamine-dependent manner [12]. 


\section{Conclusions}

Leptin is associated with parameters of inpatients' nutritional status assessments more strongly than other frequently used biochemical parameters, such as blood albumin concentration, albumin-to-CRP ratio and blood lymphocyte count. However, the use of blood leptin concentration determination as a biomarker of nutritional status should be approached carefully and needs further evaluation, especially in the context of its strong association with both current and ideal body mass, the importance of receptors' resistance to leptin, and leptin's negative relationships with muscle mass and strength.

\section{Conflict of interest: none declared}

\section{References}

1. Geisler C, Schweitzer L, Müller MJ. Functional correlates of detailed body composition in healthy elderly subjects. J Appl Physiol (1985). 2018; 124(1): 182-189, doi: 10.1152/japplphysiol.00162.2017, indexed in Pubmed: 28751368.

2. Budzyński J, Tojek K, Czerniak B, et al. Scores of nutritional risk and parameters of nutritional status assessment as predictors of in-hospital mortality and readmissions in the general hospital population. Clin Nutr. 2016; 35(6): 1464-1471, doi: 10.1016/j.clnu.2016.03.025, indexed in Pubmed: 27113120.

3. Özbilgin Ş, Hanc V, Ömür D, et al. Morbidity and mortality predictivity of nutritional assessment tools in the postoperative care unit. Medicine (Baltimore). 2016; 95(40): e5038, doi: 10.1097/MD.0000000000005038, indexed in Pubmed: 27749567.

4. Lau WB, Ohashi K, Wang Y, et al. Role of Adipokines in Cardiovascular Disease. Circ J. 2017; 81(7): 920-928, doi: 10.1253/circi.CJ-17-0458, indexed in Pubmed: 28603178.

5. Ghantous CM, Azrak Z, Hanache S, et al. Differential Role of Leptin and Adiponectin in Cardiovascular System. Int J Endocrinol. 2015; 2015: 534320, doi: 10.1155/2015/534320, indexed in Pubmed: 26064110.

6. Farr OM, Gavrieli A, Mantzoros CS. Leptin applications in 2015: what have we learned about leptin and obesity? Curr Opin Endocrinol Diabetes Obes. 2015; 22(5): 353-359, doi: 10.1097/MED.0000000000000184, indexed in Pubmed: 26313897.

7. Engin A. Endothelial dysfunction in obesity. Adv Exp Med Biol. 2017; 960: 345-79, doi: 10.1007/978-3-319-48382-5 15

8. Karvonen-Gutierrez $C A$, Zheng $H$, Mancuso $\bar{P}$, et al. Higher Leptin and Adiponectin Concentrations Predict Poorer Performance-based Physical Functioning in Midlife Women: the Michigan Study of Women's Health Across the Nation. J Gerontol A Biol Sci Med Sci. 2016; 71(4): 508-514, doi: 10.1093/gerona/glv123, indexed in Pubmed: 26302979

9. Wannamethee SG, Shaper AG, Whincup PH, et al. The obesity paradox in men with coronary heart disease and heart failure: the role of muscle mass and leptin. Int J Cardiol. 2014; 171(1): 49-55, doi: 10.1016/j. ijcard.2013.11.043, indexed in Pubmed: 24331120.

10. Flier JS, Maratos-Flier E. Leptin's Physiologic Role: Does the Emperor of Energy Balance Have No Clothes? Cell Metab. 2017; 26(1): 24-26, doi: 10.1016/j.cmet.2017.05.013, indexed in Pubmed: 28648981.
11. Hamrick MW. Role of the Cytokine-like Hormone Leptin in Muscle-bone Crosstalk with Aging. J Bone Metab. 2017; 24(1): 1-8, doi: 10.11005/jbm.2017.24.1.1, indexed in Pubmed: 28326295.

12. Ruegsegger GN, Booth FW. Running from Disease: Molecular Mechanisms Associating Dopamine and Leptin Signaling in the Brain with Physical Inactivity, Obesity, and Type 2 Diabetes. Front Endocrinol (Lausanne). 2017; 8: 109, doi: 10.3389/fendo.2017.00109, indexed in Pubmed: 28588553.

13. Guadalupe-Grau A, Larsen $S$, Guerra B, et al. Influence of age on leptin induced skeletal muscle signalling. Acta Physiol (Oxf). 2014; 211(1): 214-228, doi: 10.1111/apha.12273, indexed in Pubmed: 24605926.

14. Lipsey CC, Harbuzariu A, Daley-Brown D, et al. Oncogenic role of leptin and Notch interleukin-1 leptin crosstalk outcome in cancer. World $\mathrm{J}$ Methodol. 2016; 6(1): 43-55, doi: 10.5662/wjm.v6.i1.43, indexed in Pubmed: 27019796.

15. Frühbeck G, Catalán V, Rodríguez A, et al. Involvement of the leptin-adiponectin axis in inflammation and oxidative stress in the metabolic syndrome. Sci Rep. 2017; 7(1): 6619, doi: 10.1038/s41598-017-069970 , indexed in Pubmed: 28747790.

16. Kaiser MJ, Bauer JM, Ramsch C, et al. MNA-International Group. Validation of the Mini Nutritional Assessment short-form (MNA-SF): a practical tool for identification of nutritional status. J Nutr Health Aging. 2009; 13(9): 782-788, indexed in Pubmed: 19812868.

17. Abd-El-Gawad WM Abou-Hashem RM, EI Maraghy MO et al The validity of Geriatric Nutrition Risk Index: simple tool for prediction of nutritional-related complication of hospitalized elderly patients. Comparison with Mini Nutritional Assessment. Clin Nutr. 2014; 33(6): 1108-1116, doi: 10.1016/j.clnu.2013.12.005, indexed in Pubmed: 24418116

18. Bouillanne O, Morineau G, Dupont C, et al. Geriatric Nutritional Risk Index: a new index for evaluating at-risk elderly medical patients. Am J Clin Nutr. 2005; 82(4): 777-783, doi: 10.1093/ajcn/82.4.777, indexed in Pubmed: 16210706 .

19. Hijjawi NS, Al-Radaideh AM, Al-Fayomi KI, et al. Relationship of serum leptin with some biochemical, anthropometric parameters and abdominal fat volumes as measured by magnetic resonance imaging. Diabetes Metab Syndr. 2018; 12(3): 207-213, doi: 10.1016/j. dsx.2017.09.004, indexed in Pubmed: 28967613.

20. Fan SH, Say YH. Leptin and leptin receptor gene polymorphisms and their association with plasma leptin levels and obesity in a multi-ethnic Malaysian suburban population. J Physiol Anthropol. 2014; 33: 15, doi: 10.1186/1880-6805-33-15, indexed in Pubmed: 24947733.

21. Gubelmann C, Vollenweider P, Marques-Vidal P. Association of grip strength with cardiovascular risk markers. Eur J Prev Cardiol. 2017; 24(5): 514-521, doi: 10.1177/2047487316680695, indexed in Pubmed: 27885059.

22. Bucci L, Yani SL, Fabbri C, et al. Circulating levels of adipokines and IGF-1 are associated with skeletal muscle strength of young and old healthy subjects. Biogerontology. 2013; 14(3): 261-272, doi: 10.1007/s10522-013-9428-5, indexed in Pubmed: 23666343.

23. Rachakonda V, Borhani AA, Dunn MA, et al. Serum Leptin Is a Biomarker of Malnutrition in Decompensated Cirrhosis. PLoS One. 2016; 11(9): e0159142, doi: 10.1371/journal.pone.0159142, indexed in Pubmed: 27583675.

24. Sakuma K, Yamaguchi A. Sarcopenic obesity and endocrinal adaptation with age. Int J Endocrinol. 2013; 2013: 204164, doi: 10.1155/2013/204164, indexed in Pubmed: 23690769

25. Shida T, Akiyama K, Oh S, et al. Skeletal muscle mass to visceral fat area ratio is an important determinant affecting hepatic conditions of non-alcoholic fatty liver disease. J Gastroenterol. 2018; 53(4): 535-547, doi: 10.1007/s00535-017-1377-3, indexed in Pubmed: 28791501.

26. Padwal R, Leslie WD, Lix LM, et al. Relationship Among Body Fat Percentage, Body Mass Index, and All-Cause Mortality: A Cohort Study. Ann Intern Med. 2016; 164(8): 532-541, doi: 10.7326/M15-1181, indexed in Pubmed: 26954388.

27. Guerra B, Ponce-González JG, Morales-Alamo D, et al. Leptin signaling in skeletal muscle after bed rest in healthy humans. Eur J Appl Physiol. 2014; 114(2): 345-357, doi: 10.1007/s00421-013-2779-4, indexed in Pubmed: 24292882 